\title{
CURSOS DE ATUALIZAÇÃO PARA GRUPOS HETEROGÊNEOS
}

\section{FORMATIONS CONTINUES POUR GROUPES HÉTEROGÊNES}

TESSIER, S. Cursos de Atualização para Grupos Heterogéneos. Rev. Bras. Cresc. Des. Hum. 111(1): São Paulo, 1993.

\section{RESUMO}

A análise que precede as ações de formação deve levar em conta os aspectos relacionais e integrar a dimensão social e política a ser incorporada pelos profissionais, sabendo que cada profissional foi “construido", desde a sua formação inicial, com base em modelos rígidos e específicos, que organizam suas relações, tanto exteriores quanto interiores ao seu contexto profissional. A formação continua, organizada sob a forma de grupos heterogêneos, composta por profissionais e não profissionais (complementares ou concorrentes), da qual o autor cita três exemplos, apresenta a vantagem de colocar em contato pessoas de diferentes origens e não deve se limitar aos aspectos técnicos.

\section{RESUME}

L'analyse qui précède las actions de fommation doit lenir compre des aspects relationnels et intégrer la dimension sociale et politique que doit joiuer le personnel. Or chaque professionnel a été formé dès le début de ses études par des modèles rigides et spécifiques qui organisent leurs relations tant à l'exterieur qu'a l'interieur de leur cadre professionnel.

La formation continue organisée sous forme de groupes hétérogèaes, composés par dás professionnels et non professionnels (complémentaires ou concorrentes), dont l'auteur cite trois exemplos, presente l'avantage de mettre en contact des personnels de differentes origines afin de leurs faciliter un apprentissage direct de leurs relations.

\section{Considerações Iniciais}

O procedimento atual dos cursos de atualização é bem codificado, sobretudo no que se refere às equipes de saúde (1). Segundo esse procedimento, toda atividade de formação deve previamente analisar os cargos e as funções técnicas que essa equipe deve executar de forma a deduzir as competências que ela deve dominar e consequentemente construir o programa de formação.

Entretanto, nessa análise geralmente se omitem os aspectos relacionais do papel social e político que deve exercer o grupo. Certamente, essa omissão não é específica às atividades de formação atualizada. Na realidade ela começa desde a formação inicial, durante a qual são implicitamente inculcados os modelos de função social do profissional, específicos a cada tipo de profissão e ao seu estatuto. Reforçados que são pela separarão que isola cada formação, tais modelos são raramente contestados. Eles comandam e organizam as relações que cada um (sejam eles médicos, enfermeiros, professores ou Carteiras)

1 Pesquisador do Centre Intemational de L'Enfance - Paris - França. 
estabeleceu à sua volta e com as outras pessoas implicadas no mesmo setor de atividades. O aprendizado de tais relações fica por conta dos encontros casuais e da boa ou má vontade de cada um.

Se os cursos de atualização constituem uma ocasião de reorientar positivamente essas relações, eles devem imperativamente considerar que tais indivíduos reagem segundo modelos rígidos, cristalizados por uma experiência fortemente individualizado do exercício de suas profissões. A criação de grupos heterogéneos pode ser uma ocasião de discutir e formalizar essas relações. Pondo em contato profissionais de variados níveis, ou profissionais e não profissionais (complementares ou concorrentes), tais grupos são ordenados em tomo de temáticas comuns como o parto ou, no que nos preocupa, o encargo com a primeira infancia

A análise prévia de tais atividades de formação deve integrar a dimensão social e política do papel de cada um, não se limitando ao caráter técnico das competências necessárias. Um aspecto particularmente importante numa tal análise reside nos sistemas de gratificação e de controle a que cada um se submete ou busca atingir no exercício de sua profissão. Não se limitando tão somente aos atributos económicos, esses sistemas englobam os ganhos e perdas do estatuto familiar, social ou político no seio da comunidade.

A escolha dos participantes para estas ações de formação deve ser judiciosa e considerar as possibilidades de comunicação ou os riscos de bloqueio total, em particular diante de um observador estranho (lembremos que neste caso todo pedagogo é estranho). Os objetivos pedagógicos devem ser construídos em função dos variados níveis de conhecimento, das ambições e dos sistemas de valores que podem ser fundamentalmente diferentes entre os participantes. Limitar a análise aos aspectos técnicos poderia expor o professor a um grande malentendido inicial, cada participante interpretando os objetivos em função de seu próprio registro de leitura, forjado ao longo de sua experiênciae tendo expectativas pessoais que não serão satisfeitas.

Os métodos utilizados nestas circunstancias traduzem as preocupações de comunicação entre pessoas de diversas origens.

Os conhecimentos técnicos de base são frequentemente revisados por explanações. Na prática um auto-aprendizado, baseado em documentos distribuídos, permite evitar as intervenções magistrais muito passivas. Ele consolida também o grupo heterogêneo graças à utilização de documentos idênticos, apesar da diversidade de origens.

As observações sócio-antropológicas de campo permitem aos participantes constatar e admitir por si sós algumas realidades que nenhu- ma explanação conseguiria demonstrar. Além disso estas técnicas dão-lhes capacidades de estudos e de pesquisas comunitárias muitas vezes úteis ao seu exercício profissional.

O trabalho em grupo entre profissionais de diversas origens ou profissionais e não profissionais pode se organizar em torno de temas variados, tanto ao nivel dos conhecimentos técnicos, quanto de obsenações de campo. Em tais circunst ncias pedagógicas, esses trabalhos de grupo dão aos participantes a ocasião de exprimir sua experiência fora dos quadros hierárquicos habituais, de fazê-los sair de seus modelos rígidos e de iniciar a comunicação entre eles.

Os desempenhos de papéis colocando em cena os participantes em situações simb61icas pela sua teatralização são particularmente úteis nessas circunstancias. A organização dos participantes em dois grupos, os atores e os obsenadores, permite analisar com muita fineza as atitudes e as reações de uns e dos outros. Graças ao humor que deve ser constantemente utilizado como instrumento pedagógico, tal técnica evita as frustrações que uma crítica direta de atos reais poderia provocar.

Para ilustrar este texto, podemos descrever três exemplos de grupos heterogêneos realizados pelo Centre International de L’Enfance.

\section{Funcionamento interno de uma equipe}

$\mathrm{O}$ aprendizado das equipes regionais de saúde, constituidas de pessoas de perfis variados e complementares, visando o planejamento e a resolução de problemas, é um tema diffcil. Elaborada em diversos países (Tailândia, Tunísia e Senegal), essa técnica pedagógica estabelece e organiza os mecanismos de funcionamento de uma equipe (2). Abstraindo as equipes de seu contexto durante duas semanas e colocando-as numa outra região, o exercício baseia-se Duma análise da situação desta outra região com a proposta de soluções. O objetivo técnico é o de elaborarinstrumentos emétodos que serão aplicáveis quando do retorno a suas respectivas regiões. Esse método valoriza as experiências e perspectivas de cada membro da equipe, dando-lhe o sentido de sua própria responsabilidade e uma oportunidade de expor suas competências. Transformando as mesmas em atos de planejamento, cada um contribuí para que a equipe saia do modelo hierárquico clássico que a paralisava.

\section{Funcionamento externo da equipe}

Uma vez constituída, a equipe deve interagir com seu meio, seja ele comunitário ou fazendo parte de outros setores profissionais. Uma experiência de simulação de casos é utilizada com esse objetivo no contexto do curso de saúde da 
mãe e da criança, reunindo a cada ano profissionais de perfis variados vindos do mundo inteiro (3). Baseado numa sequência de trabalho de grupos e de desempenho de papéis, esse exercício coloca os participantes em situação de negociações comunitária e intersetorial sobre um caso que ninguém conhece mas onde cada um transpõe sua própria vivência. A análise das dinamicas da comunidade, das interpelações entre a comunidade e a equipe e entre as diferentes equipes, evidencia as lógicas de competições e as divergências de interesse. O aprendizado da identificação dessas lógicas é a primeira etapa para uma ação de mediatização.

\section{Relação intracomunitária}

A instalação de pessoal profissional de saúde numa comunidade geralmente não é objeto de uma análise avançada da situação anterior dessa mesma comunidade. Um exemplo particularmente demonstrativo (há muitos outros, sobretudo no Brasil) é a competição obstinada que prevalece entre as parteiras tradicionais e os agentes de saúde comunitários. Algumas, idosas e reconhecidas socialmente aceitam mal que jovens arrogantes venham disputar seu poder sob pretexto de terem o conhecimento de pequenas coisas modernas. Na República Centro Africana, uma série de formação conjunta de agentes de saúde comunitárias e de parteiras tradicionais permitiu repartir as fun-

\section{BIBLIOGRAFIA}

01. GUILBERT, J.J. Guide pédagogique à l'usage des professionnels de santé. 20me édition, OMS, Genève, 1990.

02. SAPIRIE, S. et THORNE, M. Guidelines for conducting district team problem-solving. In: ções entre cada parceiro, renovando entre eles o conceito de parceria. A utilização de um instrumento pedagógico idêntico para os conhecimentos técnicos reforça essa idéia de contribuição aos subjetivos comuns.

Analisando as modalidades de gratificações pretendidas por cada um, modalidades que 1) realid li Ira muitas vezes não são concorrentes, essas formações permitem valorizar os exercícios de uns e de outros, e contribuem para reconhecimentos mútuos. Nesse caso preciso, a organizaçã^O da divisão de tarefas e da repartição de poderes é o início da melhoria das relações de tipo profissional.

Cada um desses exemplos destaca a que ponto as equipes de profissionais ou de não profissionais obedecem a dinâmicas que não possuem nada de técnica e que são amplamente ignoradas nos organismos clássicos de formação. A aprendizagem das relações nos cursos de atualização é mais do que necessária. Mas para ser eficaz, tal aprendizado impõe que o próprio instrutor faça a critica de seus próprios modelos e não veicule uma concepção tecnicista e hierárquica das relações entre profissionais e com os não profissionais. No contexto que nos preocupa aqui, uma tal concepção seria bem distante das aspirações fundamentalmente comunitárias da temática do encargo com a primeira infância.

Matemal-child health and family planning. OMS, Genève, 1991, Provisional version; WHO/ MCH/FPP/91.2.

03. TESSIER, S. et PÉCHEVIS, M. Intégration des programmes de santé une application de la pédagogie parrésolution de problèmes; Cah. Etud. Rech. Francophones. Santé, 1991, 1, nº 1, Avr; pp.75-82. 